\title{
Which early life events or current environmental and lifestyle factors influence lung function in adolescents? - results from the GINIplus \& LISAplus studies
}

Agnes Luzak ${ }^{1}$, Elaine Fuertes ${ }^{1,2,3,4}$, Claudia Flexeder ${ }^{1}$, Marie Standl ${ }^{1}$, Andrea von Berg ${ }^{5}$, Dietrich Berdel ${ }^{5}$, Sibylle Koletzko ${ }^{6}$, Joachim Heinrich ${ }^{1,7,8}$, Dennis Nowak ${ }^{7,8}$ and Holger Schulz ${ }^{1,7^{*}}$

\begin{abstract}
Background: Various factors may affect lung function at different stages in life. Since investigations that simultaneously consider several factors are rare, we examined the relative importance of early life, current environmental/lifestyle factors and allergic diseases on lung function in 15-year-olds.

Methods: Best subset selection was performed for linear regression models to investigate associations between 21 diverse early life events and current factors with spirometric parameters (forced vital capacity, forced expiratory volume in $1 \mathrm{~s}$ and maximal mid-expiratory flow $\left(\mathrm{FEF}_{25-75}\right)$ in 1326 participants of the German GINIplus and LISAplus birth cohorts. To reduce model complexity, one model for each spirometric parameter was replicated 1000 times in random subpopulations $(N=884)$. Only those factors that were included in $>70 \%$ of the replication models were retained in the final analysis.

Results: A higher peak weight velocity and early lung infections were the early life events prevalently associated with airflow limitation and $\mathrm{FEF}_{25-75}$. Current environmental/lifestyle factors at age 15 years and allergic diseases that were associated with lung function were: indoor second-hand smoke exposure, vitamin $D$ concentration, body mass index (BMI) and asthma status. Sex and height captured the majority of the explained variance $(>75 \%)$, followed by BMI $(\leq 23.7 \%)$. The variance explained by early life events was comparatively low (median: 4.8\%; range: 0.2-22.4\%), but these events were consistently negatively associated with airway function.

Conclusions: Although the explained variance was mainly captured by well-known factors included in lung function prediction equations, our findings indicate early life and current factors that should be considered in studies on lung health among adolescents.
\end{abstract}

Keywords: Adolescence, Spirometry, Lung function, Determinants, Epidemiology

\footnotetext{
*Correspondence: schulz@helmholtz-muenchen.de

${ }^{1}$ Helmholtz Zentrum München - German Research Center for Environmental

Health, Institute of Epidemiology I, Ingolstädter Landstr. 1, 85764

Neuherberg, Germany

${ }^{7}$ Comprehensive Pneumology Center Munich (CPC-M), Member of the

German Center for Lung Research, Max-Lebsche-Platz 31, 81377 Munich,

Germany

Full list of author information is available at the end of the article
} 


\section{Background}

Lung development begins in early gestational age and continues until early childhood, while lung growth continues until $20-25$ years, at which point a plateau in lung function is reached [1,2]. Several factors have the potential to affect lung function during this process [1-4]. Adverse events in early life may influence lung function trajectories and lead to higher susceptibility to lung diseases, such as asthma or chronic obstructive lung disease $[1,5]$. Recently published results among children with asthma underline that the impairment of lung function in childhood is a predictor of reduced lungfunction growth and abnormal decline over time [4]. There is an increasing focus on the influence of lung function deviations in early childhood on later life respiratory morbidity [1, 4-7]. Numerous epidemiological studies have investigated factors that might influence lung function or that are associated with allergic respiratory diseases at different stages in life (Fig. 1). However, previous studies have mainly investigated only one factor or a few factors at specific periods of life, and most are focused on early life events [7-27]. In reality, it is likely that a complex framework of several factors determines an individual's lung function throughout life $[1,2,5]$. Therefore, an approach that investigates the simultaneous effects of several factors might have the potential to identify which factors may be most influential at a certain stage of life. To date, only one epidemiological study reported on the effects of several factors (including early life events, socioeconomic status and environmental factors) on spirometric lung function between 6 and 16 years of age in Tunisian children [28]. Besides well-established factors (height, weight, sex and age), this study found that type of heating had the strongest effect on lung function in healthy Tunisian children.

In the current study, we used two large, well characterized, longitudinal German birth cohort studies to investigate associations between numerous early life events and current environmental and lifestyle factors, as well as allergic diseases, with lung function assessed by spirometry in adolescents aged 15 years. Our main purpose was to identify factors associated with spirometric measures of central and peripheral airway function in adolescents and further, to examine the relative importance of early life events compared to current environmental and lifestyle factors (Fig. 1).

\section{Methods}

\section{Study population}

We used data from two prospective German birth cohorts with each 15 years of follow-up; the German Infant study on the influence of Nutrition Intervention plus air pollution and genetics on allergy development (GINIplus) [29] and the study on Life-style related factors on the development of the Immune System and Allergies in East and West Germany plus the influence of traffic emissions and genetics (LISAplus) [30]. The inclusion criteria were the same for both cohorts, German families with a full-term newborn and birth weight of at least $2500 \mathrm{~g}$ were considered as eligible.

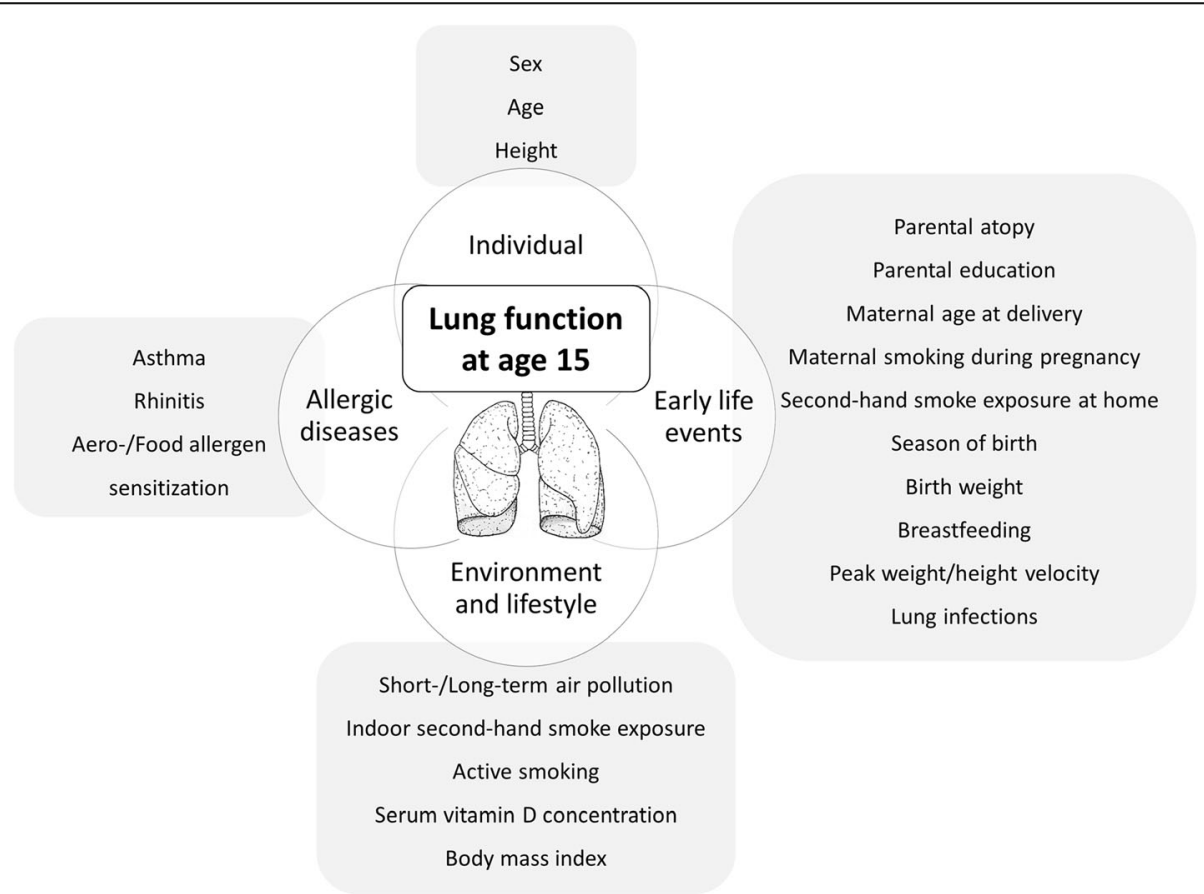

Fig. 1 Covariates investigated for association with lung function in 15-year old adolescents (definitions presented in Table 1) 
In GINIplus, 5991 neonates were recruited between 1995 and 1998 in the study centers Munich and Wesel and surrounding areas. Parents who's newborns had at least one first degree family member with an atopic disease were asked to participate in the intervention study arm, which investigated the effect of three different hydrolyzed formulas on allergy development $(N=2252)$. All others were asked to participate in the observation study arm $(N=3739)$. At the 15 -year follow-up, 1887 subjects participated in lung function measurements (50.4\% were from the intervention arm).

In LISAplus, 3094 full-term children were recruited between 1997 and 1999 in the area of four German cities: Munich, Wesel, Leipzig and Bad Honnef. Given that air pollution concentrations (an important environmental factor considered in the analysis) were only available for Munich and Wesel in GINIplus, the population of LISAplus was restricted to these study areas, comprising 1812 subjects, of which 563 participated in lung function measurements at 15 years.

In GINIplus, parent-completed questionnaires were collected at birth, yearly from 1 to 4 , and at 6,10 and 15 years of age. In LISAplus, follow-ups were at birth, $0.5,1,1.5,2,4,6,10$ and 15 years of age. The 15-year follow-up for both studies included a self-report questionnaire for the adolescents, lung function testing and blood sample collection. Further information about the cohorts' design is described elsewhere [29-31]. Data from the LISAplus and GINIplus birth cohorts were pooled and are presented for the complete study population considering study group and study center as potential confounders in the analyses.

\section{Lung function measurements}

Lung function measurements by spirometry were performed in line with ATS/ERS recommendations [32]. Participants were asked not to change their asthma medication prior to lung function testing. Among the analyzed participants, 83 had asthma. Of these, $89.2 \%$ reported asthma medication in the past 12 months. On the day of lung function testing, $7.2 \%$ reported the intake of short-acting beta agonists, 9.6\% reported the intake of inhaled corticosteroids, and $18.1 \%$ reported the intake of both inhaled corticosteroids and beta adrenergic agonists, of which most (86.7\%) consisted of longacting beta agonists.

For the performance of spirometry assessments, the technicians were equally trained and the equipment used was the same in both study centers. Flow-volume curves were obtained using a pneumotachograph-type spirometer (EasyOne Worldspirometer, ndd, Zurich, Switzerland). Subjects performed at least three and up to eight trials per test. Trial results were visually inspected according to ATS/ERS acceptability criteria [32]. Indices of the best manoeuvre, defined as the test with the largest sum of the forced expiratory volume in one second $\left(\mathrm{FEV}_{1}\right)$ and the forced vital capacity (FVC), were used in analyses. Further spirometric parameters obtained included the peak expiratory flow (PEF), the forced expiratory flow rates at $25 \%\left(\mathrm{FEF}_{25}\right), 50 \%\left(\mathrm{FEF}_{50}\right)$ and $75 \%\left(\mathrm{FEF}_{75}\right)$ of exhaled FVC and the mean flow rate between $25 \%$ and $75 \%$ of $\mathrm{FVC}\left(\mathrm{FEF}_{25-75}\right)$.

These parameters could be viewed as indicative of different lung regions or functions [33, 34]: lung volume (FVC), airways and lung volume $\left(\mathrm{FEV}_{1}\right)$, airflow limitation $\left(\mathrm{FEV}_{1} / \mathrm{FVC}\right)$, flow rates for the larger conducting $\left(\mathrm{PEF}, \mathrm{FEF}_{25}\right)$ and peripheral airways $\left(\mathrm{FEF}_{50}, \mathrm{FEF}_{75}\right.$ and $\left.\mathrm{FEF}_{25-75}\right)$. We focused our analyses and results primary on four spirometric parameters $\left(\mathrm{FVC}, \mathrm{FEV}_{1}, \mathrm{FEV}_{1} / \mathrm{FVC}\right.$ and $\left.\mathrm{FEF}_{25-75}\right)$ that represent lung volume and airway function. We also report if the associations for the primary parameters are supported by the results of the additional secondary parameters, which represent flow rates $\left(\mathrm{PEF}, \mathrm{FEF}_{25}, \mathrm{FEF}_{50}, \mathrm{FEF}_{75}\right)$. Results for the secondary parameters are presented in the additional file only.

\section{Definition of covariates}

We selected factors for investigation based on a short review of the literature, including former GINIplus and LISAplus publications [8, 9, 35, 36], and after considering the number of participants with available data in our cohorts. An overview of investigated covariates is presented in Fig. 1. A detailed description was provided in Table 1. Investigated covariates were divided in early life events (e.g. parental atopy, maternal smoking during pregnancy, season of birth, birth weight), current environmental and lifestyle factors that were assessed at the 15-year follow-up (e.g. air pollution, indoor second-hand smoke exposure, BMI), and allergic diseases (e.g. asthma, rhinitis). Besides study specific variables (study group and center), sex, age and height, which are included in lung function prediction equations [37], were considered as basic covariates. The study population comprised only Caucasians, so ethnicity was not included as covariate.

\section{Statistical analysis}

Differences between sexes and between participants included and excluded in this analysis were assessed using the t-test (normally distributed) or Wilcoxon rank-sum test (non-normally distributed) for continuous variables. The chi-square test was used for categorical variables.

Associations between study specific variables, early life events, environmental and lifestyle factors, and allergic diseases, with spirometric parameters were analyzed using linear regression. In order to determine the relevant factors, best subset selection was performed using the Mallows' Cp statistic (Cp) as the model selection criterion. The $\mathrm{Cp}$ is based on least squares estimation 


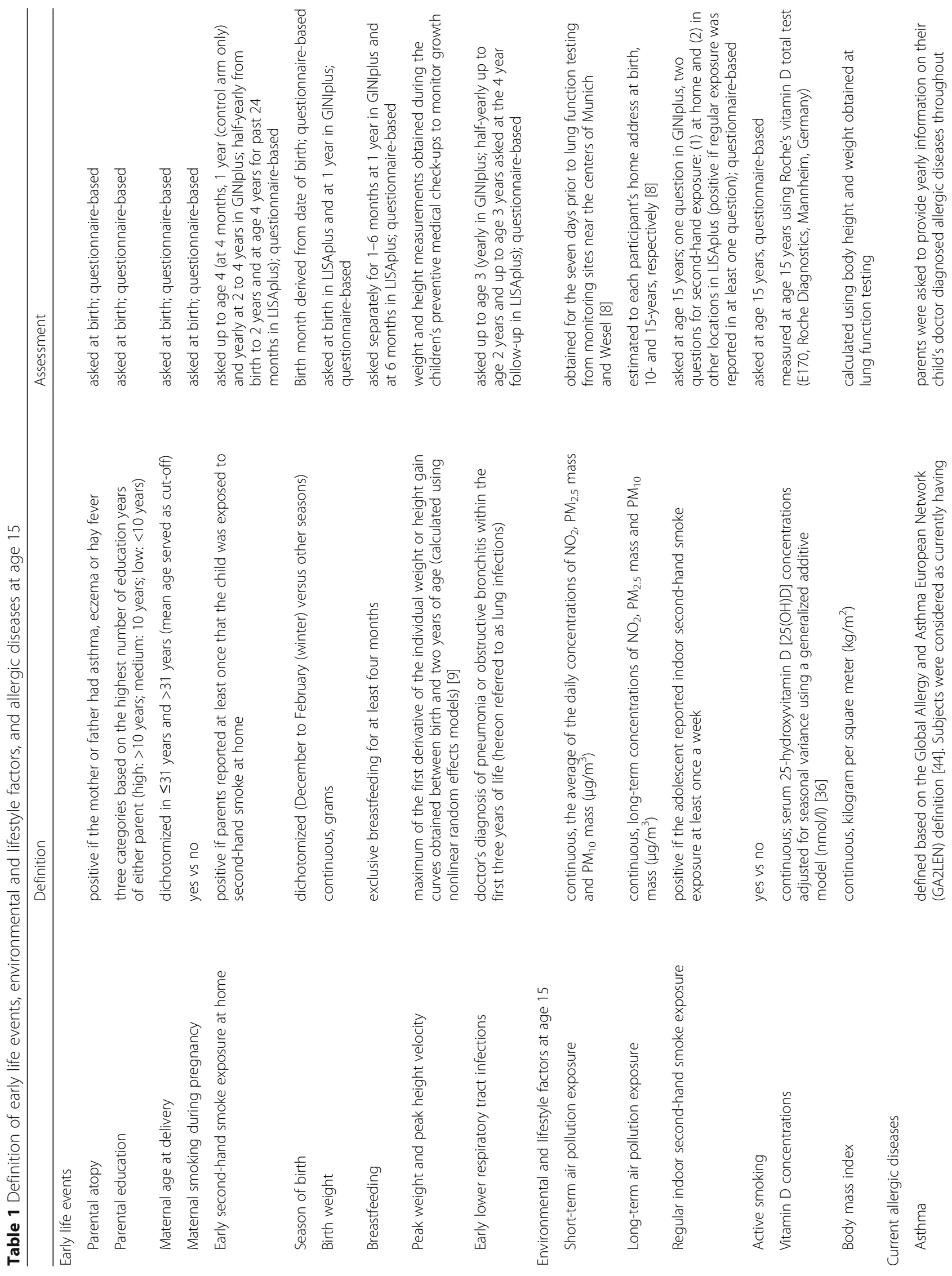




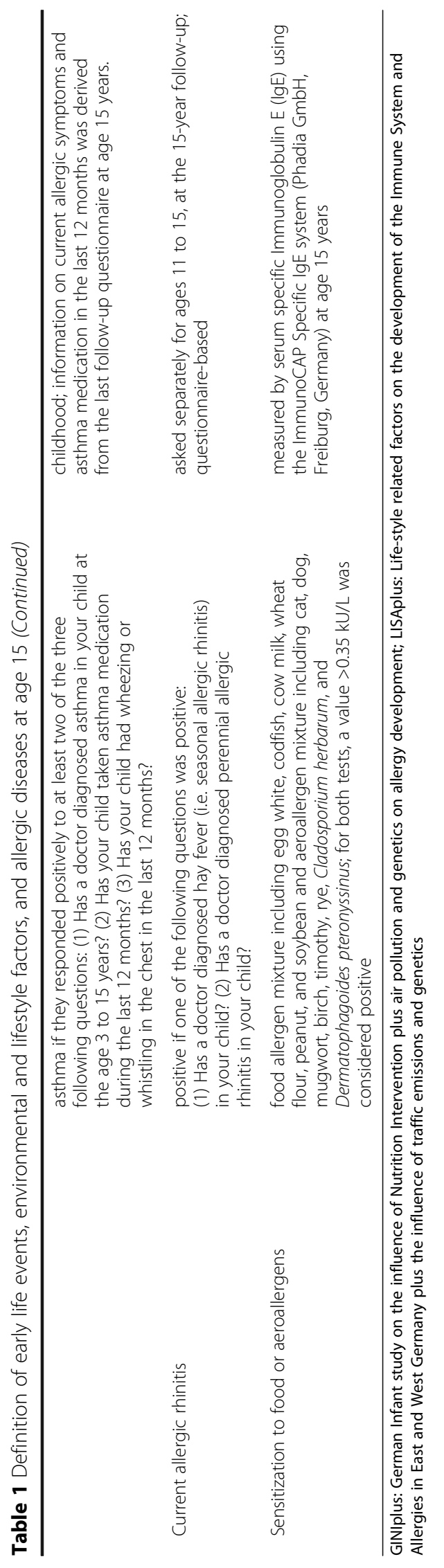


and compares the precision and bias of a full model to models with a subset of all the independent variables, taking the number of predictors into consideration [38]. Best subset selection provides the model with the lowest $\mathrm{Cp}$ for all possible model sizes of the set of all potential independent variables. The model with the lowest $\mathrm{Cp}$ among all model sizes was chosen. Categorical variables were entered using dummy coding.

To strengthen the model selection approach, we applied a two-step process. First, we performed the selection in the total population. Second, to determine if the same variables would have been selected in a subpopulation or if any variables might have been selected by random, the model selection process was repeated 1000 times with two thirds $(N=884)$ of the population randomly selected for inclusion each time. The frequency of selecting a given variable in the regression models with the lowest $\mathrm{Cp}$ (even if the variable was not necessarily significant) was assessed and compared to the variables included in the models derived using the total population. To reduce model complexity, we focused only on variables that remained in $>70 \%$ of the replication models for each particular spirometric parameter. Regression models including these selected variables (plus significant study specific variables) were rerun in the total population $(N=1326)$. Multicollinearity in the final models was assessed by the variance inflation factor (VIF), which is a measure of how much of the variance of an estimated regression coefficient is influenced by the correlation between independent variables. If correlations among variables exist, their relative importance, meaning the partial contribution to the total $\mathrm{R}^{2}$ of a regression model, is influenced by the order in which the variables are entered in a model. To adjust for possible correlations, we report the relative importance of each variable as the sequential $R^{2}$ contribution [39]. The sequential $R^{2}$ is corrected for the dependence on orderings by unweighted averaging of $\mathrm{R}^{2}$ contribution over all possible orderings. The reported results of the total sequential $\mathrm{R}^{2}$ per variable were normalized to sum up to $100 \%$ to facilitate comparability [39].

In a sensitivity analysis, current asthmatics were excluded from the final models.

Analyses were run in the statistical program R, version 3.2.0 [40]. $P$-values $<0.05$ were considered statistically significant.

\section{Results}

\section{Study population}

Valid lung function data and information on the investigated factors (Fig. 1) was available for 1326 subjects (63\% from Munich, 51\% male, mean age of 15.2 years; Table 2). Due to non-random loss to follow-up over the 15-year period, participants differed from the initial cohort, e.g. higher educated parents, more breastfeeding, lower BMI (Additional file 1: Table A1).

Mean lung function parameters were higher among boys $(p<0.05)$, with the exception of $\mathrm{FEV}_{1} / \mathrm{FVC}$, which was higher among girls (Table 2). Of 2358 participants with valid lung function measurements at the 15-year follow-up, $43.8 \%$ were excluded due to missing information on investigated factors. Lung function did not differ between the population analyzed and the other subjects with valid spirometry (Munich and Wesel) stratified by sex, with the exception that participating males had a slightly higher $\mathrm{FEV}_{1} / \mathrm{FVC}$ compared to non-participating males (Additional file 1: Table A2).

\section{Variable selection}

Nearly all early life events and current environmental and lifestyle factors that showed significant associations with lung function in the selection models based on the total population remained in $>70 \%$ of the models (Additional file 1: Tables A3 and A4). Exceptions included parental atopy ( $54 \%$ in $\mathrm{FEV}_{1} / \mathrm{FVC}$ model), parental education (52\% in $\mathrm{FEV}_{1}$ model), and regular indoor secondhand smoke exposure at age 15 (66\% in $\mathrm{FEV}_{1} / \mathrm{FVC}$ model, and slightly $<70 \%$ in $\mathrm{FEF}_{25-75}$ model), which were less often included and therefore excluded from further analyses. Linear regression results for the included variables are shown in Table 3. Results considering secondary flow rates (PEF and $\mathrm{FEF}_{25}$ to $\mathrm{FEF}_{75}$ ) are shown in the additional file 1: Tables A4 and A5. The VIF was $<2$ for all variables in the final models, suggesting low multicollinearity.

\section{Individual factors - sex, age and height}

Sex and height at lung function testing showed stable associations with all spirometric parameters, except for the association between $\mathrm{FEF}_{25-75}$ and sex and between $\mathrm{FEV}_{1}$ / FVC and height (Table 3). Associations for age were found with $\mathrm{FEV}_{1}$ and FVC. Similar results were present considering further flow rates (Additional file 1: Table A5).

\section{Early life events}

Lower lung function was associated with higher peak weight velocity and early lung infections (Table 3 ). Peak weight velocity was negatively associated with $\mathrm{FEV}_{1} /$ FVC ( $\beta:-0.8 \% / \mathrm{IQR}$ increase) and $\mathrm{FEF}_{25-75}(\beta:-88 \mathrm{ml} / \mathrm{s} /$ IQR increase). An impact of peak weight velocity on mainly the peripheral airways was also supported by the negative associations found with $\mathrm{FEF}_{50}$ and $\mathrm{FEF}_{75}$ (Additional file 1: Table A5). Early lung infections were also negatively associated with airway function as associations were found for $\operatorname{FEV}_{1}(\beta:-55 \mathrm{ml}), \mathrm{FEV}_{1} /$ FVC $(\beta:-1.1 \%)$ and $\mathrm{FEF}_{25-75}(\beta:-159 \mathrm{ml} / \mathrm{s})$, but not for FVC. Furthermore, the larger and peripheral airways appeared to be affected by early lung infections 
Table 2 Population characteristics of analyzed subjects.

\begin{tabular}{|c|c|c|c|}
\hline & Total & Males & Females \\
\hline \multirow[t]{2}{*}{$\%(N)$} & $100(1326)$ & $51.1(678)$ & $48.9(648)$ \\
\hline & \multicolumn{3}{|c|}{ Mean (SD) or \% (n) } \\
\hline Age, years & $15.2(0.3)$ & $15.2(0.3)$ & $15.2(0.3)$ \\
\hline Height*, cm & $172(8.2)$ & $176(7.4)$ & $167(6.0)$ \\
\hline \multicolumn{4}{|l|}{ Study specific } \\
\hline \multicolumn{4}{|l|}{ Study } \\
\hline GINIplus control & $38.3(508)$ & $38.2(259)$ & 38.4 (249) \\
\hline GINIplus intervention & $34.5(457)$ & $33.8(229)$ & $35.2(228)$ \\
\hline LISAplus & $27.2(361)$ & $28.0(190)$ & $26.4(171)$ \\
\hline \multicolumn{4}{|l|}{ Study center } \\
\hline Munich & $63.3(840)$ & $63.1(428)$ & $63.6(412)$ \\
\hline Wesel & $36.7(486)$ & $36.9(250)$ & $36.4(236)$ \\
\hline \multicolumn{4}{|l|}{ Early life events } \\
\hline Parental atopy, yes & $58.8(780)$ & $57.7(391)$ & $60.0(389)$ \\
\hline \multicolumn{4}{|l|}{ Parental education } \\
\hline low $(<10$ years of school) & $5.2(69)$ & $5.8(39)$ & $4.6(30)$ \\
\hline medium (= 10 years of school) & $26.7(354)$ & $27.0(183)$ & $26.4(171)$ \\
\hline high (> 10 years of school) & $68.1(903)$ & $67.3(456)$ & $69.0(447)$ \\
\hline Maternal age at delivery $>31$ years*, yes & $49.9(662)$ & $46.3(314)$ & $53.7(348)$ \\
\hline Maternal smoking during pregnancy, yes & $12.0(159)$ & $11.9(81)$ & $12.0(78)$ \\
\hline Early second-hand smoke exposure at home (up to age 4), yes & $32.7(433)$ & $32.6(221)$ & $32.7(212)$ \\
\hline Season of birth, winter & $25.6(339)$ & $24.5(166)$ & $26.7(173)$ \\
\hline Birth weight*,$g$ & $3483(442.0)$ & $3541(443.5)$ & $3422(432.6)$ \\
\hline Exclusive breastfeeding $>4$ months, yes & $60.6(804)$ & $58.3(395)$ & $63.1(409)$ \\
\hline Peak weight velocity*, $\mathrm{kg} / \mathrm{month}$ & $1.1(0.2)$ & $1.2(0.2)$ & $1.0(0.2)$ \\
\hline Peak height velocity*, $\mathrm{cm} /$ month & $3.6(0.4)$ & $3.8(0.4)$ & $3.5(0.4)$ \\
\hline Lung infections (up to age 3$)^{*}$, yes & $31.2(414)$ & $34.8(236)$ & $27.5(178)$ \\
\hline \multicolumn{4}{|l|}{ Environmental and lifestyle factors at age 15} \\
\hline \multicolumn{4}{|l|}{ Short-term air pollution } \\
\hline $\mathrm{NO}_{2}\left(\mu \mathrm{g} / \mathrm{m}^{3}\right)$ & $20.4(6.9)$ & $20.5(7.0)$ & $20.3(6.7)$ \\
\hline $\mathrm{PM}_{2.5}$ mass $\left(\mu \mathrm{g} / \mathrm{m}^{3}\right)$ & $14.7(7.3)$ & $14.4(6.7)$ & $15.0(7.9)$ \\
\hline $\mathrm{PM}_{10}$ mass $\left(\mu \mathrm{g} / \mathrm{m}^{3}\right)$ & $18.9(7.8)$ & $18.6(7.2)$ & $19.3(8.4)$ \\
\hline \multicolumn{4}{|l|}{ Long-term air pollution } \\
\hline $\mathrm{NO}_{2}\left(\mu \mathrm{g} / \mathrm{m}^{3}\right)$ & $21.2(4.8)$ & $21.2(5.0)$ & $21.2(4.6)$ \\
\hline $\mathrm{PM}_{2.5}$ mass $\left(\mu \mathrm{g} / \mathrm{m}^{3}\right)$ & $14.8(2.1)$ & $14.8(2.2)$ & $14.8(2.1)$ \\
\hline $\mathrm{PM}_{10}$ mass $\left(\mu \mathrm{g} / \mathrm{m}^{3}\right)$ & $22.1(3.2)$ & $22.0(3.3)$ & $22.1(3.2)$ \\
\hline Regular indoor second-hand smoke exposure ${ }^{a}$, yes & $20.1(266)$ & $19.0(129)$ & $21.1(137)$ \\
\hline Active smoking, yes & $5.4(71)$ & $5.6(38)$ & $5.1(33)$ \\
\hline Serum vitamin $D^{b}, \mathrm{nmol} / \mathrm{l}$ & $68.4(25.3)$ & $67.5(24.3)$ & $69.3(26.2)$ \\
\hline Body mass index* $\mathrm{kg} / \mathrm{m}^{2}$ & $20.7(3.0)$ & $20.7(3.2)$ & $20.8(2.8)$ \\
\hline \multicolumn{4}{|l|}{ Allergic diseases at age 15} \\
\hline Asthma, yes & $6.3(83)$ & $7.4(50)$ & $5.1(33)$ \\
\hline Rhinitis, yes & $18.9(251)$ & $20.9(142)$ & $16.8(109)$ \\
\hline
\end{tabular}


Table 2 Population characteristics of analyzed subjects. (Continued)

\begin{tabular}{|c|c|c|c|}
\hline Aeroallergens*, yes & $45.4(602)$ & $51.5(349)$ & $39.0(253)$ \\
\hline Food allergens, yes & $11.2(148)$ & $12.8(87)$ & $9.4(61)$ \\
\hline \multicolumn{4}{|c|}{ Spirometric parameters at age 15} \\
\hline $\mathrm{FVC}, \mathrm{I}^{*}$ & $4.08(0.77)$ & $4.50(0.74)$ & $3.64(0.51)$ \\
\hline $\mathrm{FEV}_{1}, l^{*}$ & $3.52(0.63)$ & $3.83(0.64)$ & $3.19(0.42)$ \\
\hline $\mathrm{FEV}_{1} / \mathrm{FVC}, \%^{*}$ & $86.7(6.39)$ & $85.3(6.43)$ & $88.1(6.02)$ \\
\hline$P E F, I / s^{*}$ & $7.15(1.28)$ & $7.73(1.3)$ & $6.54(0.93)$ \\
\hline $\mathrm{FEF}_{25}, \mathrm{l} / \mathrm{s}^{*}$ & $6.26(1.17)$ & $6.61(1.27)$ & $5.89(0.92)$ \\
\hline $\mathrm{FEF}_{50}, \mathrm{l} / \mathrm{s}^{*}$ & $4.46(1.05)$ & $4.71(1.14)$ & $4.19(0.87)$ \\
\hline $\mathrm{FEF}_{75}, \mathrm{l} / \mathrm{s}^{*}$ & $2.21(0.72)$ & $2.31(0.78)$ & $2.11(0.63)$ \\
\hline $\mathrm{FEF}_{25-75}, \mathrm{l} / \mathrm{s}^{*}$ & $3.92(0.92)$ & $4.12(1.01)$ & $3.70(0.77)$ \\
\hline
\end{tabular}

*Significant difference ( $p$-value $<0.05$ ) between males and females (t-test, Wilcoxon rank-sum test, or chi-square test)

${ }^{a}$ at least once a week or more. ${ }^{b}$ season-adjusted $25(\mathrm{OH}) \mathrm{D}$ concentration

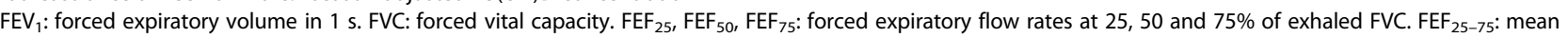
flow rate between 25 and $75 \%$ of FVC. PEF: peak expiratory flow. SD: standard deviation

as inferred from the negative associations seen with all flow rates (Additional file 1: Table A5).

While clear associations indicative of airway function and not for lung volume (FVC) were observed for peak weight velocity and early lung infections, no or only unstable associations were found for parental education, parental atopy, maternal age at delivery, maternal smoking during pregnancy, early second-hand smoke exposure at home, season of birth, birth weight, exclusive breastfeeding for at least four months and peak height velocity.

\section{Environmental and lifestyle factors at age 15}

Regular indoor second-hand smoke exposure was negatively associated with $\mathrm{FEV}_{1}(\beta:-59 \mathrm{ml}$ ) (Table 3$)$, as well as PEF and $\mathrm{FEF}_{75}$ (Additional file 1: Table A5), which supports the notion of a potential effect on the airways. Vitamin D concentrations were positively associated with FVC ( $\beta: 65 \mathrm{ml} / \mathrm{IQR}$ increase) and $\mathrm{FEV}_{1}(\beta: 32 \mathrm{ml} / \mathrm{IQR}$ increase), while the association with $\mathrm{FEV}_{1} / \mathrm{FVC}$ was negative ( $\beta$ : $-0.6 \% / \mathrm{IQR}$ increase). BMI was positively associated with FVC ( $\beta: 222 \mathrm{ml} / \mathrm{IQR}$ increase), $\mathrm{FEV}_{1}(\beta: 144 \mathrm{ml} / \mathrm{IQR}$

Table 3 Coefficients (95\%-confidence intervals) of regression models adjusted for covariates that remained stable in replication analyses

\begin{tabular}{|c|c|c|c|c|}
\hline \multirow[t]{2}{*}{ Spirometric parameter indicative of } & Lung volume & Airways \& volume & Airflow limitation & Airways \\
\hline & $\mathrm{FVC}, \mathrm{ml}$ & $\mathrm{FEV}_{1}, \mathrm{ml}$ & $\mathrm{FEV}_{1} / \mathrm{FVC}, \%$ & $\mathrm{FEF}_{25-75}, \mathrm{ml} / \mathrm{s}$ \\
\hline Sex, male & $347(289,405)$ & $220(167,274)$ & $-2.2(-2.9,-1.4)$ & \\
\hline Age, IQR years & $47(26,69)$ & $30(11,50)$ & & \\
\hline Height, IQR cm & $637(598,676)$ & $517(481,553)$ & & $508(438,577)$ \\
\hline \multicolumn{5}{|l|}{ Early life events } \\
\hline Peak weight velocity, IQR kg/month & & & $-0.8(-1.3,-0.3)$ & $-88(-155,-20)$ \\
\hline Lung infections (up to age 3), yes & & $-55(-102,-7)$ & $-1.1(-1.8,-0.3)$ & $-159(-258,-60)$ \\
\hline \multicolumn{5}{|l|}{ Environment \& lifestyle at age 15} \\
\hline Regular indoor second-hand smoke exposure ${ }^{a}$, yes & & $-59(-114,-5)$ & & \\
\hline Serum vitamin $D^{\mathrm{b}}, \mathrm{IQR} \mathrm{nmol} / \mathrm{I}$ & $65(34,96)$ & $32(3,61)$ & $-0.6(-1,-0.2)$ & \\
\hline Body mass index, $\mathrm{IQR} \mathrm{kg} / \mathrm{m}^{2}$ & $222(194,250)$ & $144(118,171)$ & $-1.2(-1.6,-0.8)$ & $85(31,140)$ \\
\hline \multicolumn{5}{|l|}{ Allergic diseases at age 15} \\
\hline Asthma, yes & $-118(-216,-21)$ & $-177(-268,-86)$ & $-1.8(-3.1,-0.4)$ & $-304(-494,-115)$ \\
\hline \multicolumn{5}{|l|}{ Study specific } \\
\hline Study (LISAplus vs GINIplus) & $68(12,124)$ & & & \\
\hline Study center (Wesel vs Munich) & $-66(-119,-13)$ & $-135(-182,-88)$ & $-1.6(-2.3,-0.9)$ & $-256(-352,-161)$ \\
\hline
\end{tabular}

All associations were statistically significant ( $p$-value $<0.05)$. Estimates for continuous variables are presented per interquartile range (IQR) increase (IQR: age $\left(0.26\right.$ years), height $(11 \mathrm{~cm})$, peak weight velocity $(0.28 \mathrm{~kg} / \mathrm{month})$, vitamin $\mathrm{D}(32.35 \mathrm{nmol} / \mathrm{l})$, body mass index $\left.\left(3.56 \mathrm{~kg} / \mathrm{m}^{2}\right)\right)$

at least once a week or more. ${ }^{\mathrm{b}}$ season-adjusted $25(\mathrm{OH}) \mathrm{D}$ concentration. $\mathrm{FEV}_{1}$ : forced expiratory volume in $1 \mathrm{~s}$. FVC: forced vital capacity. FEF $25-75$ : mean flow rate between 25 and $75 \%$ of FVC 
increase) and $\mathrm{FEF}_{25-75}(\beta: 85 \mathrm{ml} / \mathrm{s} / \mathrm{IQR}$ increase) and negatively associated with $\mathrm{FEV}_{1} / \mathrm{FVC}(\beta:-1.2 \% / \mathrm{IQR}$ increase). Positive associations between $\mathrm{BMI}$ and $\mathrm{PEF}, \mathrm{FEF}_{25}$ and $\mathrm{FEF}_{50}$ were also found (Additional file 1: Table A5).

Spirometric parameters indicative of lung volumes were positively associated with vitamin D concentrations and BMI, while regular indoor second-hand smoke exposure showed some associations with flow rates, but no clear pattern. No associations were found with short-term or long-term air pollution exposure or active smoking at age 15 (prevalence for smoking 5.4\%).

\section{Allergic diseases at age 15}

Asthma was negatively associated with all lung function measures (Table 3), while no associations were found with current allergic rhinitis, or sensitization to food or aeroallergens. This was also true considering secondary parameters for airway function, except for PEF (Additional file 1: Table A5). Exclusion of subjects with asthma from the final models did not substantially modify the associations reported for early life events and environmental and lifestyle factors at age 15 .

\section{Relative importance of factors in regression models}

The total $R^{2}$ was moderate in all models $\left(R^{2}<0.2\right)$, except for when FVC and $F E V_{1}$ were the modelled outcomes, in which case it was higher $\left(R^{2}=0.68\right.$ and $R^{2}=0.59$, respectively). As expected, the contribution to the total $\mathrm{R}^{2}$ of each model was highest for height (61.6$75.3 \%)$ and sex (23.9-27.2\%) for almost all considered indices (Table 4, Additional file 1: Table A6). Due to the varying contribution of factors to different spirometric parameters, a direct comparison of all factors and parameters is not possible. The influence of early life events was primarily detectable for airway function. The highest contribution was found for $\mathrm{FEV}_{1} / \mathrm{FVC}$ with $22.4 \%$ and $7.2 \%$ for peak weight velocity and early lung infections, respectively. However, these two early life factors contributed less than $5 \%$ to the explained variance of the other lung function parameters of airway function $\left(\mathrm{FEV}_{1}, \mathrm{FEF}_{25-75}\right)$. Among the current environmental and lifestyle factors, vitamin $\mathrm{D}$ concentrations $\left(\leq 2.1 \%\right.$, maximum in $\left.\mathrm{FEV}_{1} / \mathrm{FVC}\right)$ and regular indoor second-hand smoke exposure $\left(0.2 \%\right.$ in $\left.\mathrm{FEV}_{1}\right)$ contributed less than BMI, which contributed to almost all parameters (range $3.2 \%$ in $\mathrm{FEF}_{25-75}$ to $23.7 \%$ in $\mathrm{FEV}_{1} / \mathrm{FVC}$ ).

\section{Discussion}

Early life events, such as peak weight velocity and early lung infections, as well as current lifestyle factors, such as BMI, indoor second-hand smoke exposure and serum vitamin D concentrations, were associated with several spirometric parameters at age 15 years. The results of our study also confirm the well-established evidence supporting a role of sex, height and asthma status on lung function.

Among the early life events, a higher peak weight velocity was associated with airflow limitation and lower peripheral flow rates. Further, early lung infections were negatively associated with all lung function parameters except lung volume, suggesting that early lung infections may lead to low, long-term airflow limitation. A study by Svanes et al. reported an association of early childhood disadvantage factors, e.g. respiratory infections, maternal smoking and others, with lower lung function in adults and also a larger decline in lung function over time [6]. Early structural and functional changes on the developing or growing lung might lead to an impaired lung function and a higher susceptibility to lung diseases, but possible underlying mechanisms are not fully understood yet $[1,5,6]$.

Regular indoor second-hand smoke exposure at age 15 years was associated with somewhat poorer airway function. The relative contribution of indoor secondhand smoke exposure was relatively low and no clear pattern with the lung function parameters could be determined. Higher vitamin D concentrations were primarily associated with volumetric indices, and with some airflow limitation, but with relatively small effects $\left(<2.5 \%\right.$ of $\left.\mathrm{R}^{2}\right)$. After height and sex, BMI contributed the most to the explained variance for nearly all spirometric parameters. BMI was positively associated with all lung function parameters indicative of lung volume and airway function, but also with airflow limitation. Similar associations have been reported in other studies among youth $[15,21]$.

Except for BMI, the relative importance of early life events and environmental and lifestyle factors was relatively low, in comparison to the contribution of sex and height. Nevertheless, early life events were primarily negatively associated with parameters indicative of airway function, while no associations were found for lung volume. This suggests that early life factors should be considered in studies focusing on airway function. Regular indoor second-hand smoke exposure at age 15, an environmental and lifestyle factor, showed the same tendency. On the contrary, positive associations were detected for vitamin D concentration with volumetric parameters and for BMI with both, volumes and airway function. Given the associations between higher weight gain in the first 2 years of life and current BMI with the spirometric indices, it appears that body weight at several points in life is important for lung function.

Associations of lung function with peak weight velocity $[26,27]$, lower respiratory infections $[10,14,41]$, BMI [15, 21], vitamin D concentrations [16, 17] and second-hand smoke exposure $[18,20]$ have been also 
Table 4 Relative importance of variables in final regression models (averaged $R^{2}$ contribution)

\begin{tabular}{|c|c|c|c|c|c|c|c|}
\hline \multirow{2}{*}{\multicolumn{4}{|c|}{ Spirometric parameter indicative of }} & $\begin{array}{l}\text { Lung } \\
\text { volume }\end{array}$ & $\begin{array}{l}\text { Airways \& } \\
\text { volume }\end{array}$ & $\begin{array}{l}\text { Airflow } \\
\text { limitation }\end{array}$ & Airways \\
\hline & & & & FVC & $\mathrm{FEV}_{1}$ & $\mathrm{FEV}_{1} / \mathrm{FVC}$ & $\mathrm{FEF}_{25-75}$ \\
\hline \multicolumn{4}{|c|}{ Total $\mathbf{R}^{2}$ of the model } & 0.68 & 0.59 & 0.12 & 0.18 \\
\hline \multicolumn{4}{|l|}{ Sex } & 26.1 & 23.9 & 27.2 & \\
\hline \multicolumn{4}{|l|}{ Age } & 1.1 & 1.0 & & \\
\hline \multicolumn{4}{|l|}{ Height } & 61.6 & 65.2 & & 75.3 \\
\hline \multicolumn{8}{|c|}{ Early life events } \\
\hline \multicolumn{4}{|c|}{ Peak weight velocity } & & & 22.4 & 4.8 \\
\hline \multicolumn{4}{|c|}{ Lung infections (up to age 3 ) } & & 0.2 & 7.2 & 3.8 \\
\hline \multicolumn{8}{|c|}{ Environment \& lifestyle at age 15} \\
\hline \multicolumn{4}{|c|}{$\begin{array}{l}\text { Regular indoor second-hand smoke } \\
\text { exposure }^{1}\end{array}$} & & 0.2 & & \\
\hline \multicolumn{4}{|c|}{ Serum vitamin $D^{2}$} & 0.5 & 0.3 & 2.1 & \\
\hline \multicolumn{4}{|c|}{ Body mass index } & 10.2 & 7.3 & 23.7 & 3.2 \\
\hline \multicolumn{8}{|c|}{ Allergic diseases at age 15} \\
\hline \multicolumn{4}{|l|}{ Asthma } & 0.2 & 0.9 & 5.0 & 4.8 \\
\hline \multicolumn{8}{|c|}{ Study specific } \\
\hline \multicolumn{4}{|c|}{ Study (LISAplus vs GINIplus) } & 0.2 & & & \\
\hline \multicolumn{4}{|c|}{ Study center (Wesel vs Munich) } & 0.2 & 1.0 & 12.4 & 8.2 \\
\hline$<1 \%$ & $<3 \%$ & $<5 \%$ & $<10 \%$ & $<15 \%$ & $\geq 15 \%$ & & \\
\hline
\end{tabular}

Relative importance of variables in regression models adjusted for covariates that remained stable in replication analyses are displayed as normalized percent of $R^{2}$ contribution averaged (unweighted) over variable orderings.

${ }^{1}$ at least once a week or more. ${ }^{2}$ season-adjusted $25(\mathrm{OH}) \mathrm{D}$ concentration. $\mathrm{FEV}_{1}$ : forced expiratory volume in 1 s. FVC: forced vital capacity. $\mathrm{FEF}_{25-75}$ : mean flow rate between 25 and $75 \%$ of FVC

found in other studies. Only one previous study investigated associations between several early life events and current lifestyle factors with lung function [28]. This crosssectional study investigated Tunisian children with an age range of 6-16 years (92 participants were 14-16 years old and would be comparable to our population). Similar to our results, associations between lung function with sex, height and weight were found. Strong associations with age were also reported [28], whereas the more narrow age distribution in our analysis was only associated with some spirometric parameters. As in our study, no associations between normal birth weight and lung function were observed in this previous publication [28]. Kotecha et al. reported an association between birth weight and lung function at age 8-9 years, but not at age 14-17 years, suggesting that the importance of early factors on lung function might differ by age [13].

As a complex framework of factors influences lung function $[1,2]$, we considered several early life and current environmental and lifestyle factors in adolescence to identify factors associated with lung function and their relative importance at age 15 . Correlations, interactions or modulating effects between some investigated factors are very likely and study specific population characteristics might influence the impact and contribution of single factors. Study center was shown to be associated with lung function in our cohort but might partially stand as a surrogate for other factors not captured by our data. For example, there might be differences in lifestyle and environmental factors between the included rural (Wesel) and urban (Munich) areas.

Due to loss to follow-up, the prevalence of low education $(<10$ years of school) among the participants' parents was only $5.2 \%$, which may partially explain why socioeconomic status did not remain in the main models. In contrast to our results, a review covering different countries and age ranges showed that low socioeconomic status was associated with reduced lung 
function [42]. The underrepresentation of less educated families in our study might have also led to a lack of association with some factors that are correlated with socioeconomic status, such as maternal smoking during pregnancy (prevalence 12\%), which otherwise, has been shown to have a negative effect in previous studies $[18,20]$. Furthermore, results of a study among schoolchildren in Canada suggested a modifying effect of socioeconomic status on the association of air pollution and traffic exposure with respiratory symptoms and lung function [43]. In this study, a tendency for a higher risk of respiratory symptoms and lower lung function associated with traffic or air pollution exposure was seen in less educated households, although most associations were not statistically significant [43].

\section{Strengths and limitations}

A major strength of this study is the investigation of a full range of standardized measured and visually inspected spirometric lung function parameters indicative of lung volume, as well as less often investigated lung function measures of larger conducting and peripheral airways, in two prospective birth cohorts. Furthermore, information on a broad range of early life events, environmental and lifestyle factors, and allergic diseases at age 15 was available for 1326 German adolescents, enabling this rarely applied comprehensive approach. Further factors that were available only in a subset of our population (986 subjects $(74 \%)$ ) e.g. having $<2$ or $\geq 2$ siblings at age 15 (one variable for older, another for younger siblings), using gas for cooking and having mold at home, both asked in the first year of life, and daycare center attendance during the first three years of life would not have been included in the final models (based on best subset selection in this reduced population). This result and the limited data availability for these factors led to their exclusion from the main analysis. The inclusion of physical activity assessed by accelerometry would also have diminished our sample size to 721 subjects (54\%) and was not shown to be associated with lung function in our cohort [35].

A major limitation of this study is selective loss to follow-up. For example, participants included in the analysis had higher parental education, more breastfeeding and less maternal smoking during pregnancy (Additional file 1: Table A1). Our results might therefore not be generalizable to all German adolescents. It is possible that covariates that were not associated with lung function in our population could play a role in others, pointing out a need for replication in other, larger studies. Further, study center (Munich/Wesel) was associated with lung function in our study population, which might suggest regional environmental and lifestyle differences not captured by the considered factors.
Our use of the Cp statistic as a selection criterion for automatic model selection might have resulted in the selection of a group of variables that would not have been selected using a different selection criterion (e.g. adjusted $\mathrm{R}^{2}$ ). To reduce model complexity, we chose to use the $\mathrm{Cp}$ statistic because it penalizes the number of included variables. Further, we replicated our analysis $(N=1000)$ in randomly chosen subpopulations to reduce potential selection bias attributable to influential cases.

\section{Conclusions}

In addition to well-known measures included in lung function prediction equations (sex and height), as well as current asthma and BMI, our study showed that among a variety of factors considered in our analysis, weight gain and pulmonary infections during infancy were prevalent factors associated with lung function in 15year-olds. While the early life factors were primarily associated with airway function, factors at age 15 showed associations with airway function as well as lung volume. Although our findings require replication in independent studies, they nevertheless highlight the need to include specific early life events and current lifestyle factors in studies on lung health among adolescents and suggest that effective health promotion should exist at all ages.

\section{Additional files}

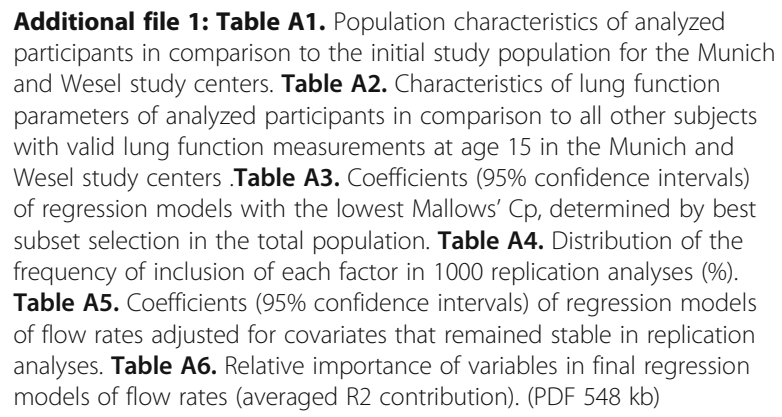
and Wesel study centers. Table A2. Characteristics of lung function parameters of analyzed participants in comparison to all other subjects with valid lung function measurements at age 15 in the Munich and Wesel study centers .Table A3. Coefficients (95\% confidence intervals) of regression models with the lowest Mallows' $\mathrm{Cp}$, determined by best subset selection in the total population. Table A4. Distribution of the frequency of inclusion of each factor in 1000 replication analyses (\%). Table A5. Coefficients (95\% confidence intervals) of regression models of flow rates adjusted for covariates that remained stable in replication analyses. Table A6. Relative importance of variables in final regression models of flow rates (averaged R2 contribution). (PDF 548 kb)

\section{Abbreviations}

BMI: Body mass index $\left(\mathrm{kg} / \mathrm{m}^{2}\right) ; \mathrm{FEF}_{25}$ : Forced expiratory flow rate at $25 \%$ of exhaled FVC; FEF $25-75$ : Mean flow rate between 25 and $75 \%$ of FVC; $\mathrm{FEF}_{50}$ : Forced expiratory flow rate at $50 \%$ of exhaled FVC; FEF 75 : Forced expiratory flow rate at $75 \%$ of exhaled FVC; $F_{E V}$ : Forced expiratory volume in $1 \mathrm{~s}$; FVC: Forced vital capacity; GINIplus: German Infant study on the influence of Nutrition Intervention plus air pollution and genetics on allergy development; LISAplus: Life-style related factors on the development of the Immune System and Allergies in East and West Germany plus the influence of traffic emissions and genetics; $\mathrm{NO}_{2}$ : Nitrogen dioxide; PEF: Peak expiratory flow; $\mathrm{PM}_{10}$ : Particulate matter with diameters $<10 \mu \mathrm{m} \mathrm{PM}_{2.5}$ : Particulate matter with diameters $<2.5 \mu \mathrm{m}$; SD: Standard deviation. VIF: variance inflation factor

\section{Acknowledgements}

The authors thank all the families for their active participation in the GINIplus study and the LISAplus study. Furthermore, we thank all members of the GINIplus Study Group and the LISAplus Study Group for their excellent work. The GINIplus Study Group consists of the following: Helmholtz Zentrum München - German Research Center for Environmental Health, Institute of 
Epidemiology I, Neuherberg (Heinrich J, Brüske I, Schulz H, Standl M, Schnappinger M, Ferland M, Thiering E, Tiesler C, Flexeder C, Zeller C); Marien-Hospital Wesel, Research Institute, Department of Pediatrics, Wesel (Berdel D, von Berg A, Filipiak-Pittroff B); Ludwig-Maximilians-University of Munich, Dr. von Hauner Children's Hospital, Munich (Koletzko S); Child and Adolescent Medicine, University Hospital rechts der Isar of the Technical University Munich (Bauer CP, Hoffmann U); IUF - Leibniz Research Institute for Environmental Medicine, Düsseldorf (Schikowski T, Hoffmann B, Link E, Klümper C, Krämer U, Sugiri D).

The LISAplus Study Group consists of the following: Helmholtz Zentrum München - German Research Center for Environmental Health, Institute of Epidemiology I, Munich (Heinrich J, Brüske I, Schulz H, Standl M, Schnappinger M, Ferland M, Thiering E, Tiesler C, Flexeder C, Zeller C); Municipal Hospital 'St Georg', Department of Pediatrics, Leipzig (Borte M, Diez U, Dorn C, Braun E); Marien-Hospital Wesel, Research Institute, Department of Pediatrics, Wesel (von Berg A, Berdel D, Stiers G, Maas B); Pediatric Practice, Bad Honnef (Schaaf B); Helmholtz Centre of Environmental Research - UFZ, Department of Environmental Immunology/Core Facility Studies, Leipzig (Lehmann I, Bauer M, Herberth G, Müller J, Röder S, Nowak M, Schilde M); Technical University Munich, Department of Pediatrics, Munich (Bauer CP, Hoffmann U, Paschke M, Marra S); Technical University Munich, Center of Allergy and Environment Munich (ZAUM), Munich (Ollert M, Grosch J).

\section{Funding}

The GINIplus study was mainly supported for the first 3 years by the Federal Ministry for Education, Science, Research and Technology (interventional arm) and Helmholtz Zentrum Munich (former GSF) (observational arm). The 4 year, 6 year, 10 year and 15 year follow-up examinations of the GINIplus study were covered from the respective budgets of the 5 study centers (Helmholtz Zentrum Munich (former GSF), Research Institute at MarienHospital Wesel, LMU Munich, TU Munich, and from 6 years onwards also from IUF - Leibniz Research-Institute for Environmental Medicine at the University of Düsseldorf) and a grant from the Federal Ministry for Environment (IUF Düsseldorf, FKZ 20462296). Further, the 15 year follow-up examination of the GINIplus study was supported by the Commission of the European Communities, the 7th Framework Program: MeDALL project, and as well by the companies Mead Johnson and Nestlé. The LISAplus study was mainly supported by grants from the Federal Ministry for Education, Science, Research and Technology and in addition from Helmholtz Zentrum Munich (former GSF), Helmholtz Centre for Environmental Research - UFZ, Leipzig, Research Institute at Marien-Hospital Wesel, Pediatric Practice, Bad Honnef for the first 2 years. The 4 year, 6 year, 10 year and 15 year follow-up examinations of the LISAplus study were covered from the respective budgets of the involved partners (Helmholtz Zentrum Munich (former GSF), Helmholtz Centre for Environmental Research UFZ, Leipzig, Research Institute at Marien-Hospital Wesel, Pediatric Practice, Bad Honnef, IUF - Leibniz-Research Institute for Environmental Medicine at the University of Düsseldorf) and in addition by a grant from the Federal Ministry for Environment (IUF Düsseldorf, FKZ 20462296). Further, the 15 year follow-up examination of the LISAplus study was supported by the Commission of the European Communities, the 7th Framework Program: MeDALL project. This work was additionally supported by the Comprehensive Pneumology Center Munich (CPC-M), a member of the German Center for Lung Research.

\section{Availability of data and materials}

The authors confirm that, for approved reasons, restrictions apply to the availability of the data underlying the findings. The informed consent given by the GINIplus and LISAplus study participants does not cover providing individual data in public databases. Interested researchers may request a de-identified dataset from the corresponding author Holger Schulz (schulz@helmholtz-muenchen.de).

\section{Authors' contributions}

$A L, D N$ and $H S$ were involved in the conception and design of the study. $C F, E F, M S, A v B, D B, S K, J H$ and $H S$ contributed with data acquisition and data coding and AL with statistical analyses. AL, DN and HS contributed to the interpretation of the findings. AL drafted the manuscript and all authors revised it critically for important intellectual content and approved the final version.

\section{Ethics approval and consent to participate}

The study protocols were approved by the local ethics committees (Bavarian General Medical Council, University of Leipzig, Medical Council of NorthRhine-Westphalia) and written consent was obtained from all participating families.

\section{Consent for publication}

Not applicable.

\section{Competing interests}

The authors declare that they have no competing interests.

\section{Publisher's Note}

Springer Nature remains neutral with regard to jurisdictional claims in published maps and institutional affiliations.

\begin{abstract}
Author details
${ }^{1}$ Helmholtz Zentrum München - German Research Center for Environmental Health, Institute of Epidemiology I, Ingolstädter Landstr. 1, 85764 Neuherberg, Germany. ${ }^{2}$ ISGlobal, Centre for Research in Environmental Epidemiology (CREAL), Doctor Aiguader 88, 08003 Barcelona, Spain. ${ }^{3}$ Universitat Pompeu Fabra (UPF), Plaça de la Mercè 10, 08002 Barcelona, Spain. ${ }^{4}$ CIBER Epidemiología y Salud Pública (CIBERESP), Av. Monforte de Lemos, 3-5. Pabellón 11, 28029 Madrid, Spain. ${ }^{5}$ Department of Pediatrics, Research Institute, Marien-Hospital Wesel, Pastor-Janßen-Str. 8-38, 46483 Wesel, Germany. ${ }^{6} \mathrm{Dr}$ von Hauner Children's Hospital,

Ludwig-Maximilians-University of Munich, Lindwurmstr. 4, 80337 Munich, Germany. ${ }^{7}$ Comprehensive Pneumology Center Munich (CPC-M), Member of the German Center for Lung Research, Max-Lebsche-Platz 31, 81377 Munich, Germany. Institute and Outpatient Clinic for Occupational, Social and Environmental Medicine, University Hospital of Munich (LMU), Ziemssenstr. 1, 80336 Munich, Germany.
\end{abstract}

Received: 4 November 2016 Accepted: 3 July 2017

Published online: 12 July 2017

\section{References}

1. Stocks J, Hislop A, Sonnappa S. Early lung development: lifelong effect on respiratory health and disease. Lancet Respir Med. 2013;1:728-42.

2. Merkus PJ. Effects of childhood respiratory diseases on the anatomical and functional development of the respiratory system. Paediatr Respir Rev. 2003;4:28-39.

3. Carlsen $\mathrm{KC}$, Haland G, Carlsen $\mathrm{KH}$. Natural history of lung function in health and diseases. Curr Opin Allergy Clin Immunol. 2009;9:146-50.

4. McGeachie MJ, Yates KP, Zhou X, Guo F, Sternberg AL, Van Natta ML, et al. Patterns of growth and decline in lung function in persistent childhood asthma. N Engl J Med. 2016;374:1842-52.

5. Duijts $L$, Reiss IK, Brusselle G, de Jongste JC. Early origins of chronic obstructive lung diseases across the life course. Eur J Epidemiol. 2014;29:871-85.

6. Svanes C, Sunyer J, Plana E, Dharmage S, Heinrich J, Jarvis D, et al. Early life origins of chronic obstructive pulmonary disease. Thorax. 2010;65:14-20.

7. Dratva J, Zemp E, Dharmage SC, Accordini S, Burdet L, Gislason T, et al. Early life origins of lung ageing: early life exposures and lung function decline in adulthood in two European cohorts aged 28-73 years. PLoS One. 2016;11: e0145127.

8. Fuertes E, Bracher J, Flexeder C, Markevych I, Klümper C, Hoffmann B, et al. Long-term air pollution exposure and lung function in 15 year-old adolescents living in an urban and rural area in Germany: the GINIplus and LISAplus cohorts. Int J Hyg Environ Health. 2015;218:656-65.

9. Flexeder C, Thiering E, von Berg A, Berdel D, Hoffmann B, Koletzko S, et al. Peak weight velocity in infancy is negatively associated with lung function in adolescence. Pediatr Pulmonol. 2016;51:147-56.

10. Bonnelykke K, Vissing NH, Sevelsted A, Johnston SL, Bisgaard H. Association between respiratory infections in early life and later asthma is independent of virus type. J Allergy Clin Immunol. 2015;136:81-86.e4.

11. Jaakkola JJ, Nafstad P, Magnus P. Environmental tobacco smoke, parental atopy, and childhood asthma. Environ Health Perspect. 2001;109:579-82.

12. Soto-Ramirez N, Alexander M, Karmaus W, Yousefi M, Zhang H, Kurukulaaratchy RJ, et al. Breastfeeding is associated with increased lung function at 18 years of age: a cohort study. Eur Respir J. 2012;39:985-91. 
13. Kotecha SJ, Watkins WJ, Henderson AJ, Kotecha S. The effect of birth weight on lung spirometry in white, school-aged children and adolescents born at term: a longitudinal population based observational cohort study. J Pediatr. 2015;166:1163-7.

14. Puig C, Friguls B, Gomez M, Garcia-Algar O, Sunyer J, Vall O. Relationship between lower respiratory tract infections in the first year of life and the development of asthma and wheezing in children. Arch Bronconeumol. 2010;46(10):514-21.

15. Cibella F, Bruno A, Cuttitta G, Bucchieri S, Melis MR, De Cantis S, et al. An elevated body mass index increases lung volume but reduces airflow in Italian schoolchildren. PLoS One. 2015;10:e0127154.

16. Niruban SJ, Alagiakrishnan K, Beach J, Senthilselvan A. Association between vitamin D and respiratory outcomes in Canadian adolescents and adults. J Asthma. 2015;52:653-61.

17. Yao TC, Tu YL, Chang SW, Tsai HJ, Gu PW, Ning HC, et al. Serum 25hydroxyvitamin $D$ levels in relation to lung function and exhaled nitric oxide in children. J Pediatr. 2014;165:1098-103. e1

18. Moshammer H, Hoek G, Luttmann-Gibson H, Neuberger MA, Antova T, Gehring $U$, et al. Parental smoking and lung function in children: an international study. Am J Respir Crit Care Med. 2006;173:1255-63.

19. Gehring U, Gruzieva O, Agius RM, Beelen R, Custovic A, Cyrys J, et al. Air pollution exposure and lung function in children: the ESCAPE project. Environ Health Perspect. 2013;121:1357-64.

20. Cook DG, Strachan DP, Carey IM. Health effects of passive smoking. 9. Parental smoking and spirometric indices in children. Thorax. 1998;53:884-93.

21. He QQ, Wong TW, Du L, Jiang ZQ, Qiu H, Gao Y, et al. Respiratory health in overweight and obese Chinese children. Pediatr Pulmonol. 2009;44:997-1002.

22. Slachtova $H$, Gehring $U$, Hoek G, Tomaskova H, Luttmann-Gibson H, Moshammer $\mathrm{H}$, et al. Parental education and lung function of children in the PATY study. Eur J Epidemiol. 2011;26:45-54.

23. Brockow I, Zutavern A, Hoffmann U, Grubl A, von Berg A, Koletzko S, et al. Early allergic sensitizations and their relevance to atopic diseases in children aged 6 years: results of the GINI study. J Investig Allergol Clin Immunol. 2009;19(3):180-7.

24. Corbo GM, Agabiti N, Forastiere F, Dell'Orco V, Pistelli R, Kriebel D, et al. Lung function in children and adolescents with occasional exposure to environmental tobacco smoke. Am J Respir Crit Care Med. 1996;154:695-700.

25. Gold DR, Wang X, Wypij D, Speizer FE, Ware JH, Dockery DW. Effects of cigarette smoking on lung function in adolescent boys and girls. N Engl J Med. 1996;335:931-7.

26. van der Gugten AC, Koopman M, Evelein AM, Verheij TJ, Uiterwaal CS, van der Ent CK. Rapid early weight gain is associated with wheeze and reduced lung function in childhood. Eur Respir J. 2012;39:403-10.

27. den Dekker HT. Sonnenschein-van der Voort AM, de Jongste JC, AnessiMaesano I, Arshad SH, Barros H, et al. Early growth characteristics and the risk of reduced lung function and asthma: a meta-analysis of 25,000 children. J Allergy Clin Immunol. 2016;137:1026-35.

28. Trabelsi Y, Paries J, Harrabi I, Zbidi A, Tabka Z, Richalet JP, et al. Factors affecting the development of lung function in Tunisian children. Am J Hum Biol. 2008;20:716-25.

29. von Berg A, Krämer U, Link E, Bollrath C, Heinrich J, Brockow I, et al. Impact of early feeding on childhood eczema: development after nutritional intervention compared with the natural course - the GINIplus study up to the age of 6 years. Clin Exp Allergy. 2010:40:627-36.

30. Heinrich J, Bolte G, Hölscher B, Douwes J, Lehmann I, Fahlbusch B, et al. Allergens and endotoxin on mothers' mattresses and total immunoglobulin E in cord blood of neonates. Eur Respir J. 2002;20:617-23.

31. Heinrich J, Brüske I, Schnappinger M, Standl M, Flexeder C, Thiering E, et al. Die zwei deutschen Geburtskohorten GINIplus and LISAplus. Bundesgesundheitsblatt. 2012;55:864-74.

32. Miller MR, Hankinson J, Brusasco V, Burgos F, Casaburi R, Coates A, et al Standardisation of spirometry. Eur Respir J. 2005;26:319-38.

33. Quanjer PH, Tammeling GJ, Cotes JE, Pedersen OF, Peslin R, Yernault J-C. Lung volumes and forced ventilatory flows. Eur Respir J. 1993;6:5-40.

34. McNulty W, Usmani OS. Techniques of assessing small airways dysfunction. European Clinical Respiratory Journal. 2014;1: doi:10.3402/ecrj.v1.25898.

35. Smith MP, von Berg A, Berdel D, Bauer CP, Hoffmann B, Koletzko S, et al. Physical activity is not associated with spirometric indices in lung-healthy German youth. Eur Respir J. 2016;48:428-40.

36. Flexeder C, Thiering E, Koletzko S, Berdel D, Lehmann I, von Berg A, et al. Higher serum 25(OH)D concentrations are associated with improved FEV1 and FVC in adolescence. Eur Respir J. 2017;49:1601804.
37. Quanjer PH, Stanojevic S, Cole TJ, Baur X, Hall GL, Culver BH, et al. Multiethnic reference values for spirometry for the 3-95-yr age range: the global lung function 2012 equations. Eur Respir J. 2012;40:1324-43.

38. Miller AJ. Subset Selection in Regression. 2nd Edition. Boca Raton: Chapman \& Hall/CRC; 2002

39. Groemping U. Relative Importance for Linear Regression in R: The Package relaimpo. J Stat Softw. 2006;17(1)1-27.

40. R Core Team. R: A language and environment for statistical computing. Vienna: R Foundation for Statistical Computing; 2015. URL http://www.Rproject.org/. Accessed 8 Aug 2016.

41. Chan JY, Stern DA, Guerra S, Wright AL, Morgan WJ, Martinez FD. Pneumonia in childhood and impaired lung function in adults: a longitudinal study. Pediatrics. 2015;135:607-16.

42. Hegewald MJ, Crapo RO. Socioeconomic status and lung function. Chest. 2007:132:1608-14.

43. Cakmak S, Hebbern C, Cakmak JD, Vanos J. The modifying effect of socioeconomic status on the relationship between traffic, air pollution and respiratory health in elementary schoolchildren. J Environ Manag. 2016;177:1-8.

44. Lodrup Carlsen KC, Haland G, Devulapalli CS, Munthe-Kaas M, Pettersen M, Granum B, et al. Asthma in every fifth child in Oslo, Norway: a 10-year follow up of a birth cohort study. Allergy. 2006;61:454-60.

\section{Submit your next manuscript to BioMed Central and we will help you at every step:}

- We accept pre-submission inquiries

- Our selector tool helps you to find the most relevant journal

- We provide round the clock customer support

- Convenient online submission

- Thorough peer review

- Inclusion in PubMed and all major indexing services

- Maximum visibility for your research

Submit your manuscript at www.biomedcentral.com/submit
C) Biomed Central 